\title{
Budget impact analysis of the new reimbursement policy for day surgery in Thailand
}

This article was published in the following Dove Medical Press journal: Risk Management and Healthcare Policy

\section{Rapeepong \\ Suphanchaimat ${ }^{1,2}$ \\ Jutatip Thungthong ${ }^{3}$ \\ Kriddhiya Sriprasert ${ }^{3}$ \\ Kanjana Tisayaticom' \\ Chulaporn Limwattananon ${ }^{4}$ \\ Supon Limwattananon ${ }^{4}$ \\ 'International Health Policy Program (IHPP), Ministry of Public Health, \\ Nonthaburi, Thailand; ${ }^{2}$ Bureau of Epidemiology, Department of Disease Control, Ministry of Public Health, Nonthaburi, Thailand; ${ }^{3}$ National Health Security Office, Bangkok, Thailand; ${ }^{4}$ Faculty of Pharmaceutical Sciences, Khon Kaen University, Khon Kaen, Thailand}

Correspondence: Rapeepong Suphanchaimat

International Health Policy Program (IHPP), Ministry of Public Health, Mueng District, Nonthaburi, I I000, Thailand

Tel +6625902366

Fax +6625902385

Email rapeepong@ihpp.thaigov.net
Introduction: In 2017 the Thai Ministry of Public Health proposed a new financing mechanism to promote day surgery under the Universal Coverage Scheme - the main public insurance arrangement for Thais. The key feature of the policy is health facilities performing day surgery can claim the treatment expense based on relative weight (RW) instead of adjusted RW (adjRW). Procedures for 12 diseases (so-called "candidate procedures") are eligible for the new reimbursement. The objective of this study was to assess the current day surgery situation in Thailand and analyze potential budget impact from the new policy.

Methods: A quantitative cross-section design was employed. Individual inpatient records of the Universal Coverage Scheme during 2014-2016 were analyzed. Descriptive statistics and simulation analyses were applied. The analyses were divided into three subtopics: 1) case volume and expense claim, 2) utilization across facilities, and 3) case mix index and budget impact.

Results: Overall, day surgery accounted for $4.8 \%$ of admissions with candidate procedures. Inguinal hernias, hemorrhoids, and common bile duct stones caused the largest sum of admission numbers and admission days. Currently, the annual reimbursement for candidate procedures treated as inpatient cases is around 290.8 million Baht (US\$ 8.8 million), with about 12.4 million Baht (US\$ 0.38 million) for day surgery cases. If all candidate procedures were performed as day surgery and diagnostic-related groups (DRG) version 6 was applied, the incremental budget would amount to 1.9 million Baht (US\$ 58,903).

Conclusions: The new reimbursement policy will likely lead to minimal budget burden. Even in the case of maximal uptake of the policy, the needed budget would increase by just $15 \%$. The marginal budget increment was explained by the infinitesimal RW-adjRW difference. Apart from the financial measure, other qualitative aspects of the policy, such as infrastructure and health staff readiness, should be explored.

Keywords: day surgery, inpatient, budget impact, case mix index, Thailand

\section{Introduction}

At the turn of the 20th century, the foundations of modern day surgery were laid in the UK. Since then, it took over a century for the concept of modern day surgery to be undertaken by health professionals all over the globe. A gradual increase in the opening of day surgery units in Australia, Canada, the UK, and the US was observed, particularly between the 1970s and the 1980s. ${ }^{1}$ From 1989 to 2003, the percentage of elective surgery performed on a day basis rose significantly, from $15 \%$ to $70 \%{ }^{1}$ This situation also spawned a series of academic papers discussing the benefits of day surgery in terms of not only clinical outcomes but also economic advantages. For instance, 
Gurusamy et $\mathrm{al}^{2}$ conducted meta-analysis comparing day-case laparoscopic cholecystectomy (LC) with overnight stay LC. The study found no significant differences between day case and overnight stay with respect to several clinical outcomes, such as morbidity, readmission incidence, patient satisfaction, and return to normal activity and work. ${ }^{2}$ Mitchell and Harrow $^{3}$ reported that treatment costs for day-case hernia surgery were $56 \%$ less than the costs for conventional inpatient cases. The finding was congruent with prior research by Shepard et al, ${ }^{4}$ revealing that the cost for day-case herniorrhaphy was around US\$39 compared with US\$149 in traditional inpatient operation-a 4-fold difference.

While many countries have adopted measures/policies to promote day surgery in their routine health care practice-for instance, the UK Department of Health has proposed day surgery as the "default" for the vast majority of patients requiring surgery - in Thailand day surgery has not been considered as "default" in the Thai health care system, despite the fact that some hospitals have already performed day surgery as the routine practice. ${ }^{1,5}$ Srisawasdi et $\mathrm{al}^{6}$ estimated that day surgery prevalence in Thailand constituted about $6.6 \%$ among all elective surgical cases with a slow rate of expansion. One of the key explanations is a lack of nationwide policies to promote day surgery in the Thai health care system.

Recently, in 2017, the Department of Medical Services (DMS) of the Thai Ministry of Public Health (MOPH) has proposed a new financing policy to promote day surgery to the National Health Security Office (NHSO). The NHSO is the governing body of the Universal Coverage Scheme (UCS) - the main public insurance arrangement for almost all Thai citizens. ${ }^{6}$ The UCS is financed by general tax. Health care providers are paid by capitation for outpatient care and by diagnostic-related groups (DRG) with global budget for inpatient care. . $^{78}$

The key content of the policy is the UCS-contracted health facilities can be reimbursed the treatment expense of each admission that contains day surgery from the NHSO through standard relative weight (RW) in lieu of adjusted relative weight (adjRW). In detail, for the routine DRG claiming system, the claim in each admission is calculated from the multiplication of 1) RW, which is a proxy of disease severity, treatment complexity, discharge status, and clinical outcomes and 2) base rate in terms of Baht per RW. Yet, the RW needs to be converted to adjRW first (commonly known as "case mix index" [CMI]), before plugging in the reimbursement formula, provided that the length of stay of that admission does not lie within a standard range. ${ }^{9}$ For instance, if a treatment for a specific disease normally requires a length of stay between 2 and 5 days - coming up with an RW of X units, but due to some reasons the patient is admitted in the hospital for less than a day, the latter admission will result in an "adjRW" of Y units. Generally, an adjRW is smaller than its corresponding RW (in this example, $\mathrm{Y}$ is less than $\mathrm{X})$, ceteris paribus. Thus, the change of the reimbursement formula by using RW instead of adjRW in the UCS payment mechanism is intended to incentivize providers to boost day surgery cases.

The DMS, in consultation with the Royal College of Surgery, set the criteria for day-surgery reimbursement as presented in Table 1 . Note that only 12 diseases with the related surgical procedures (so-called "candidate procedures") were eligible for the reimbursement. ${ }^{10}$

There are several terms under the family of "day surgery," and different literature uses them differently_ "same day surgery," "ambulatory surgery," "outpatient surgery," and "short stay surgery," to name but a few. ${ }^{11-13}$ These terms are usually used interchangeably despite some nuanced differences. ${ }^{14}$ Note that the definition of "day surgery" proposed by the DMS is quite different from the term "day surgery" commonly used in the UK and in much international literature. ${ }^{5,15}$ The classic definition of day surgery used in the UK is quite clear - the patient must be admitted and discharged on the same calendar day, with day surgery as the planned management ${ }^{16,17}$ — while the DMS' definition referred to a surgical case admitted in and discharged from a facility within 24 hours. To this end, the term "day surgery" is more lineated to "23-hours stay surgery" or to "short stay surgery" than the UK definition. ${ }^{12,13}$

The new financing policy on day surgery is in a very early stage. It still lacks evidence to help inform policymakers regarding the current situation of day surgery in Thailand and its potential budget impact if the new payment policy is in effect. Therefore, to fill these gaps in knowledge, the objective of this study is to assess the present state of day surgery in Thailand through various angles, including case volumes, length of stay, and economic burden, and analyze additional budget impact which may arise from the new payment policy.

\section{Methods}

This study employed a quantitative cross-section design. The dataset acquired was all individual inpatient records of the UCS in fiscal year (FY) 2014-2016. STATA software version 14 (serial number $=401406358220$ ) was used for data analysis. Descriptive statistics (using frequency, mean, and median) was applied. The analysis was divided into three subtopics: 1) volume of cases and monetary claim for treatment 
Table I Preconditions for health care cost reimbursement for day surgery

\begin{tabular}{|c|c|}
\hline Criteria & Details \\
\hline $\begin{array}{l}\text { Definition of day surgery } \\
\text { admission }\end{array}$ & The admission must have $<24$-hours length of stay and contain at least one of the "candidate procedures". \\
\hline Patient condition & $\begin{array}{l}\text { The patient must not have comorbidity and complication as defined by the fifth digit of the DRG coding; that is, } \\
\text { the fifth digit of the DRG must be zero. }\end{array}$ \\
\hline Discharge condition & The discharge condition must be "improved". \\
\hline Health facility condition & The facility must have full time surgeons in function and standard operating theaters. \\
\hline \multirow[t]{11}{*}{$\begin{array}{l}\text { Candidate procedures }{ }^{\mathrm{a}} \text { for } \\
12 \text { diseases }^{\mathrm{b}} \text { of interest }\end{array}$} & $\begin{array}{l}\text { I. Inguinal hernia-The patient must undergo one of the following procedures: } 53.00,53.01,53.02,53.03,53.04 \text {, } \\
53.05,53.10,53.12,53.13,53.14,53.15,53.16,53.17,53.21,53.29,53.31 \text {, and } 53.39 \text {. }\end{array}$ \\
\hline & 2. Hydrocele-The patient must undergo the procedure, 61.2 but must not undergo the procedure, 61.91 . \\
\hline & 3. Hemorrhoid-The patient must undergo one of the following procedures: $49.44,49.45,49.46$, and 49.49 . \\
\hline & $\begin{array}{l}\text { 4. Vaginal bleeding-The patient must undergo one of the following procedures: } 68.16,68.21,68.22,68.23 \text {, and } \\
68.29 \text {. }\end{array}$ \\
\hline & $\begin{array}{l}\text { 5. Esophagogastric varice-The patient must undergo one of the following procedures: } 42.33,43.4 \mathrm{I} \text {, and } 44.43 \text {; } \\
\text { and the patient must be diagnosed of one of the following codes: } 185.0 \text {, I85.9, and } 186.4 \text {. }\end{array}$ \\
\hline & 6. Esophagogastric stricture-The patient must undergo one of the following procedures: 44.22 and 42.92. \\
\hline & $\begin{array}{l}\text { 7. Esophagogastric cancer with obstruction-The patient must undergo one of the following procedures: } 42.33 \\
\text { and } 42.8 \mathrm{I} \text {; and the patient must be diagnosed of one of the following codes: } \mathrm{CI} 5 \text { and } \mathrm{Cl} 6 \text {. }\end{array}$ \\
\hline & $\begin{array}{l}\text { 8. Colorectal polyp-The patient must undergo one of the following procedures: } 45.42 \text { (but not with } 45.4 \mathrm{I} \text { ) } \\
\text { and } 45.43 \text { (but not with } 45.42 \text { ); and the patient must be diagnosed of one of the following codes: DI2.6, } \\
\text { K63.5, K62.0, and K62.I. }\end{array}$ \\
\hline & $\begin{array}{l}\text { 9. CBD stone-The patient must undergo one of the following procedures: } 5 \mathrm{I} .85,5 \mathrm{I} .86,5 \mathrm{I} .87 \text {, and } 5 \mathrm{I} .88 \text {; and } \\
\text { the patient must be diagnosed of one of the following codes: } \mathrm{K} 80.0, \mathrm{~K} 80 . \mathrm{I}, \mathrm{K} 80.2, \mathrm{~K} 80.3, \mathrm{~K} 80.4 \text {, and } \mathrm{K} 80.5 \text {. }\end{array}$ \\
\hline & $\begin{array}{l}\text { 10. Pancreatic duct stone-The patient must undergo one of the following procedures: } 51.85,52.93 \text {, and } 52.94 \text {; } \\
\text { and the patient must be diagnosed of one of the following codes: K86.8. }\end{array}$ \\
\hline & $\begin{array}{l}\text { II. Bile duct stricture-The patient must undergo one of the following procedures: } 51.85,5 \mathrm{I} .86 \text {, and } 51.87 \text {; and } \\
\text { the patient must be diagnosed of one of the following codes: } \mathrm{C} 22 . \mathrm{I}, \mathrm{K} 82.0, \mathrm{~K} 82.8, \mathrm{~K} 83 . \mathrm{I}, \mathrm{K} 83.8, \mathrm{~K} 9 \mathrm{I} .8, \mathrm{C} 23 \text {, } \\
\mathrm{C} 24 \text {, and } \mathrm{C} 25 \text {. } \\
\text { 12. Pancreatic duct stricture-The patient must undergo one of the following procedures: } 52.93,52.97 \text {, and } \\
52.98 \text {; and the patient must be diagnosed of one of the following codes: K83.I, K83.8, K86.0, K86.I, K9I.8, } \\
\text { and } \mathrm{C} 25 \text {. }\end{array}$ \\
\hline
\end{tabular}

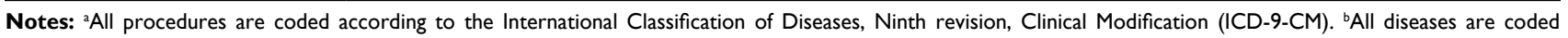
according to the International Classification of Diseases, Tenth revision (ICD-I0).

Abbreviations: $C B D$, common bile duct; DRG, diagnostic-related group.

expense, 2) differences of day surgery cases across facility types, and 3) CMI analysis and additional budget impact. Note that the analysis in subtopic 3 used only the dataset in the latest year (FY 2016) instead of the whole three FY. This is because FY 2016 was likely to better reflect the most updated situation of day surgery and its budget encountered.

There are a few points that should be taken into account in the analysis. First, the UCS is the main purchaser to "all" contracted facility types, not only the MOPH hospitals. There exist several facility types under the UCS, namely, 1) small district hospitals and health centers (DH-F \& HC), 2) medium-to-large district hospitals (DH-M), 3) general or provincial hospitals $(\mathrm{GH}), 4)$ regional hospitals $(\mathrm{RH})$, 5) university hospitals $(\mathrm{UH}), 6)$ private hospitals $(\mathrm{PH}), 7)$ specialized hospitals ( $\mathrm{SH}$ ), such as psychiatric hospitals and skin hospitals, 8) hospitals not affiliated to the MOPH $(\mathrm{OH})$, such as police hospitals and military hospitals, and 9) other facilities that cannot be classified in any types above, such as autonomous public organization hospitals and hospitals under municipalities or local government units. Second, the current reimbursement system for inpatient care in Thailand is based on DRG version 5, and there has been a discussion in the MOPH that DRG version 6 (which is under developed) will replace DRG version 5 in the following year. As the new reimbursement policy and DRG version 6 have not been fully in effect, it is difficult to estimate the exact budget impact. Hence, this study assumed that there might be six different scenarios which emerged from the new reimbursement policy, ranging from a status quo scenario to maximal policy uptake scenario, Table 2.

It should be noted that, for scenario A3 and B3, the figure $15 \%$ was derived from a consultative meeting between the researchers and policymakers from the DMS. At present, there were around $4.8 \%$ of candidate procedures performed as a day case (this figure is later detailed in the "Results" section). The researchers then randomly selected an addition 
of $10.2 \%$ of the admissions performing candidate procedures to make the total bulk of day surgery cases amount to $15 \%$ of the candidate procedures. The selection was done over 100 rounds (100 simulations) to account for random uncertainty; then mean of the incremental budget over these 100 simulations was calculated. The extra budget impact nationwide was simply equal to the sum of the multiplication between RW-adjRW difference and base rate in each admission that contains candidate procedures and has a length of stay $<24$ hours (Figure 1).

Table 2 Scenarios for budget impact analysis

\begin{tabular}{|l|l|l|}
\hline \multirow{2}{*}{ Scenarios } & Details \\
\cline { 2 - 3 } & $\begin{array}{l}\text { \% of day surgery admissions } \\
\text { compared to all admissions } \\
\text { with candidate procedures }\end{array}$ & $\begin{array}{l}\text { Version } \\
\text { of DRG }\end{array}$ \\
\hline AI (status quo) & 4.8 & 5 \\
\hline A2 (maximum) & 100 & 5 \\
\hline A3 (moderate) & 15 & 5 \\
\hline BI (status quo) & 4.8 & 6 \\
\hline B2 (maximum) & 100 & 6 \\
\hline B3 (moderate) & 15 & 6 \\
\hline
\end{tabular}

Abbreviation: DRG, diagnostic-related group.

\section{Results}

\section{Volume of cases and current claim}

The total number of all admissions of the UCS inpatients between FY 2014 and FY 2016 was 17,643,854. If limited to surgical cases only, there were 3,531,253 admissions. About $2.4 \%$ of the surgical admissions (85,724 admissions) experienced candidate procedures. Among the admissions with candidate procedures, inguinal hernia was the most common diagnosis ( 20,324 admissions per year), followed by hemorrhoid $(\sim 3,469$ admissions per year) and common bile duct (CBD) stone ( 1,813 admissions per year). The least prevalent diagnosis was pancreatic duct stone $(\sim 10$ admissions per year). The results showed a relatively stable trend amongst the three FYs, with slight increases in some procedures (Figure 2).

Regarding length of stay, all 12 procedures constituted over 331,643 admission days ( 110,548 days per year). Inguinal hernia, hemorrhoid, and CBD stone were the topthree diagnoses that had the largest sum of admission days, whereas esophagogastric cancer (CA) \& obstruction, pancreatic duct stone, and pancreatic stricture were diagnoses with

Admission with length of stay $\leq 24$ hours (day surgery)

All admissions with canditate procedures

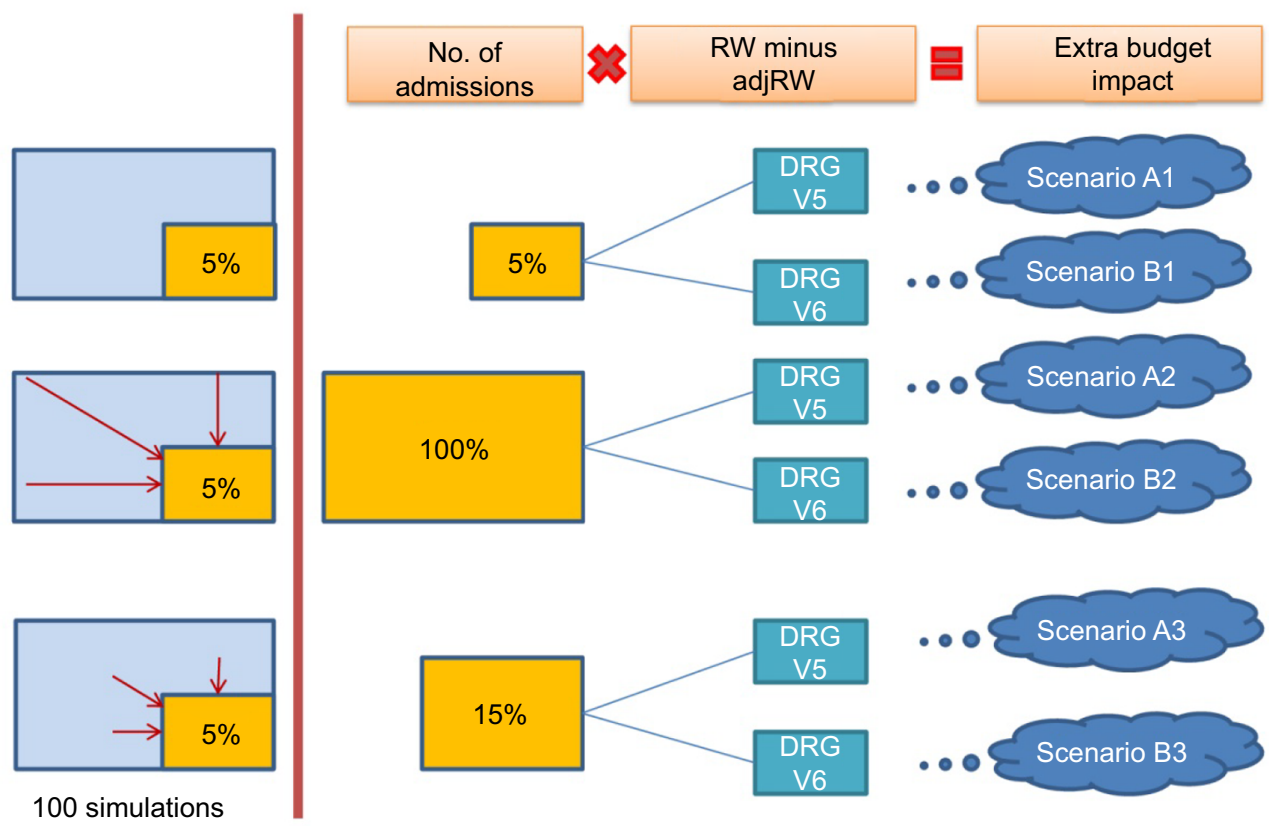

Figure I Graphical demonstration of the approach for budget impact analysis.

Notes: Scenario: AI = DRG version 5 and day surgery cases account for $5 \%$ of candidate procedures. A2 = DRG version 5 and day surgery cases account for $100 \%$ of candidate procedures. A3 = DRG version 5 and day surgery cases account for $15 \%$ of candidate procedures. BI = DRG version 6 and day surgery cases account for $5 \%$ of candidate procedures. B2 = DRG version 6 and day surgery cases account for $100 \%$ of candidate procedures. B3 = DRG version 6 and day surgery cases account for $15 \%$ of candidate procedures.

Abbreviations: adjRW, adjusted relative weight; DRG, diagnostic-related group; RW, relative weight; $V$, version. 
| FY 2014 | $\mathrm{FY} 2015$ | $\mathrm{FY} 2016$

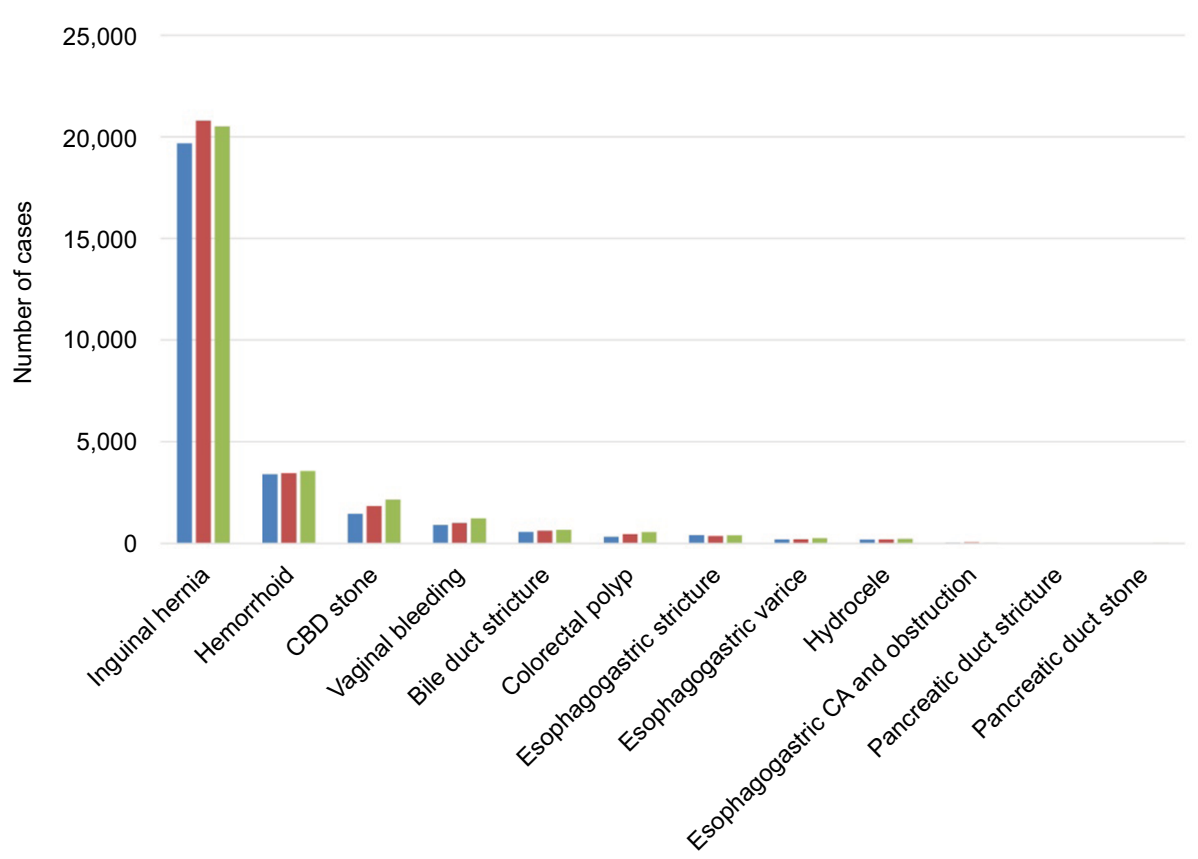

Figure 2 Diagnoses of admissions with candidate procedures between FY 2014 and FY 2016.

Abbreviations: $\mathrm{CA}$, cancer; $\mathrm{CBD}$, common bile duct; FY, fiscal year.

longest mean length of stay. Correspondingly, inguinal hernia accounted for the greatest monetary claim (235.5 million Baht or US\$ 7.7 million per year), followed by CBD stone and hemorrhoid. Esophagogastric CA \& obstruction saw the largest mean expense claim. The total claim for all candidate procedures amounted to 417.2 million Baht per year (US\$12.6 million). This meant that, in the case of maximal take up of policy where all candidate procedures were undertaken as day surgery, the sum of length of stay would be tantamount to the accumulation of admission volumes. Accordingly, the annual claim would proportionately decline to 104.4 million Baht (US\$3.2 million) - a three-quarter decrease (Table 3).

About $4.8 \%$ of all diagnoses containing candidate procedures met the criteria for day surgery. Esophagogastric varice had the largest proportion of day surgery cases compared with other diagnoses (Table 4).

In all diagnoses of day surgery admissions, the proportion of "improved" discharge status was over 90\% (mean $=98.9 \%$ ), and the readmission incidence was less than $5 \%$ $($ mean $=0.7 \%)($ Table 5$)$.

\section{Differences of day surgery cases across facility types}

Overall, the majority of admissions with candidate procedures took place in regional and provincial hospitals. Pancreatic duct stricture, pancreatic duct stone, and esophagogastric stricture were relatively more concentrated in university hospitals (Figure 3).

When confining the analysis to day cases only, the distribution of cases still followed a similar pattern as presented in Figure 3, despite a few differences, that is, procedures for complicated diagnoses (pancreatic duct stricture, pancreatic duct stone, and esophagogastric CA \& obstruction) were all performed in the university hospitals (Figure 4).

\section{CMI analysis and additional budget impact $\mathrm{CMI}$ analysis}

Should DRG version 5 be in effect, inguinal hernia, CBD stone, and hemorrhoid were the top-three diagnoses contributing to the largest sum of RW and adjRW nationwide. CBD stone, pancreatic duct stricture, and bile duct stricture were diagnoses with the greatest mean RW and mean adjRW. If focused on day admissions only, inguinal hernia, hemorrhoid, and vaginal bleeding were the top-three diagnoses with the largest sum of RW and adjRW. In general, RW was about $0.03 \%-0.27 \%$ larger than adjRW for all procedures. This difference was more pronounced in CBD stone, bile duct stricture, pancreatic duct stone, pancreatic duct stricture, and esophagogastric CA \& obstruction, where the RW-adjRW difference was $>5 \%$. 


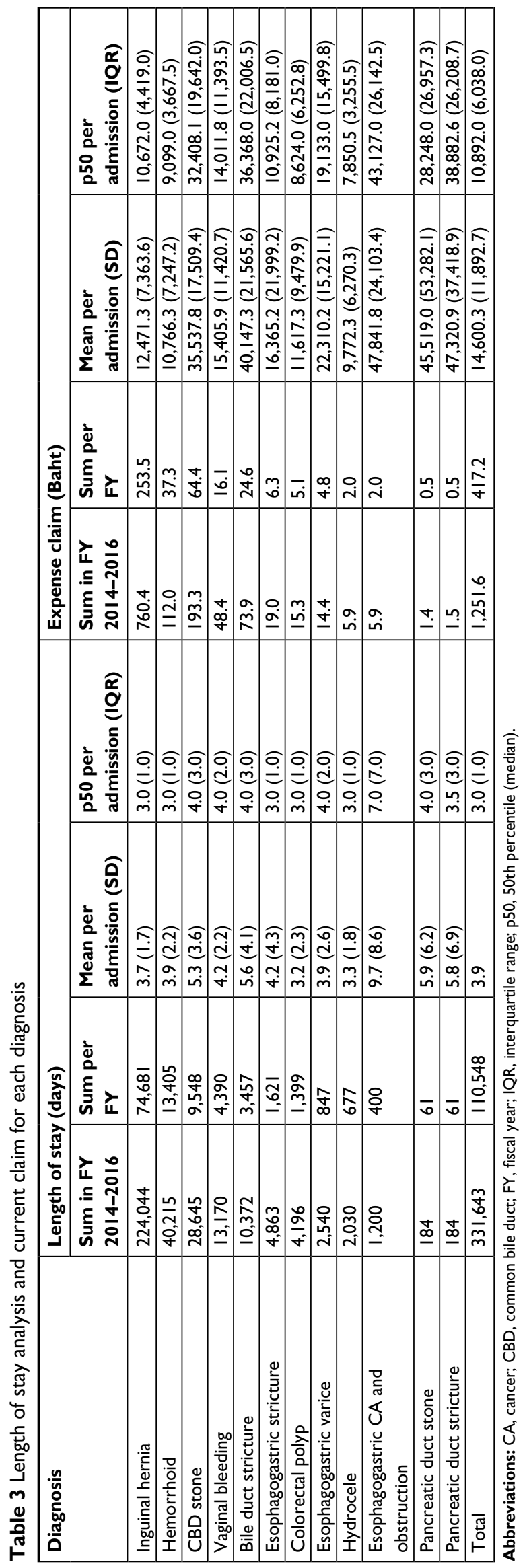

Should DRG version 6 be promulgated, RW and adjRW of all candidate procedures would increase by varying degrees. The increase was apparent in relatively complicated diseases, such as pancreatic duct stricture, where its RW would expand from 2.70 for DRG version 5-3.46 for DRG version 6 (28\% increase). The detailed results of CMI analysis are presented in Figure 5 and Tables 6-9.

\section{Additional budget impact}

FY 2016 saw 29,593 admissions with candidate procedures. Among these admissions, 1,577 had a length of stay shorter than 24 hours. According to the current reimbursement policy (total reimbursement $=$ adjRW $\times$ base rate), the total budget reimbursed to health facilities for inpatient care undergoing candidate procedures was about 290.8 million Baht (US\$8.8 million) per year for DRG version 5, and 324.0 million Baht (US\$9.8 million) per year for DRG version 6. If counted only day surgery, the total reimbursement would amount to 12.4 million Baht (US\$0.38 million) for DRG version 5 and 12.8 million Baht (US\$0.39 million) for DRG version 6, Figure 6.

Should the new reimbursement policy be promulgated (total reimbursement $=\mathrm{RW} \times$ base rate), the incremental budget impact would vary between 0.18 and 1.94 million Baht (US\$5,530-US\$58,903), depending on assumptions. Scenario A1 would cause the least additional budget, whereas scenario B2 would lead to the greatest extra budget impact (Figure 7).

Regional hospitals, university hospitals, and general hospitals were the top-three facility types that benefited most from the new reimbursement policy (Figure 8).

\section{Discussion}

Overall, day surgery specified by the DMS constituted around $0.5 \%$ of all admissions of the UCS patients or $4.8 \%$ of the admissions with candidate procedures. Inguinal hernia, hemorrhoid, and CBD stone were the top-three diagnoses that caused the largest sum of admission volume and admission days. The proportion of "improved" to all discharge conditions was over $90 \%$ among all day surgery cases, with $\mathrm{a}<1 \%$ readmission rate. Most complicated diagnoses, such as pancreatic duct stone and pancreatic duct stricture, were concentrated in university and regional hospitals, whereas less complicated diagnoses were more concentrated in district and general hospitals. Inguinal hernia, CBD stone, and hemorrhoid rendered the largest sum of RW and adjRW nationwide. Given the reimbursement policy at the status quo, the NHSO annually subsidized the inpatient treatment cost for all candidate procedures by around 290.8 million Baht 
Table 4 Proportion of day surgery admissions for each diagnosis

\begin{tabular}{|c|c|c|c|}
\hline & \multicolumn{2}{|c|}{ No. of admissions between FY 2014 and FY 2016} & \multirow{2}{*}{$\begin{array}{l}\text { \% day surgery } \\
(b /(a+b))\end{array}$} \\
\hline & Length of stay $>24$ hours (a) & Length of stay $\leq 24$ hours (b) & \\
\hline Esophagogastric varice & 540 & 105 & 16.3 \\
\hline Pancreatic duct stone & 26 & 5 & 16.1 \\
\hline Colorectal polyp & 1,118 & 203 & 15.4 \\
\hline Vaginal bleeding & 2,766 & 378 & 12.0 \\
\hline Pancreatic duct stricture & 29 & 3 & 9.4 \\
\hline Hemorrhoid & 9,585 & 822 & 7.9 \\
\hline Hydrocele & 565 & 41 & 6.8 \\
\hline Esophagogastric stricture & 1,094 & 68 & 5.9 \\
\hline Inguinal hernia & 58,643 & 2,330 & 3.8 \\
\hline Bile duct stricture & $\mathrm{I}, 796$ & 45 & 2.4 \\
\hline CBD stone & 5,365 & 73 & 1.3 \\
\hline Esophagogastric CA and obstruction & 123 & 1 & 0.8 \\
\hline Total & 81,650 & 4,074 & 4.8 \\
\hline
\end{tabular}

Abbreviations: $\mathrm{CA}$, cancer; $\mathrm{CBD}$, common bile duct; $\mathrm{FY}$, fiscal year.

Table 5 Discharge status of each diagnosis for day surgery admissions

\begin{tabular}{|l|l|l|}
\hline & \% improved & $\begin{array}{l}\text { \% readmission } \\
\text { (all causes) }\end{array}$ \\
\hline Inguinal hernia & 99.4 & 0.5 \\
\hline Hydrocele & 97.6 & 0.0 \\
\hline Hemorrhoid & 98.5 & 0.5 \\
\hline Vaginal bleeding & 98.4 & 1.1 \\
\hline Esophagogastric varice & 94.3 & 1.9 \\
\hline Esophagogastric stricture & 95.6 & 2.9 \\
\hline $\begin{array}{l}\text { Esophagogastric CA and } \\
\text { obstruction }\end{array}$ & 100.0 & 0.0 \\
\hline Colorectal polyp & & \\
\hline CBD stone & 99.0 & 0.5 \\
\hline Pancreatic duct stone & 100.0 & 4.1 \\
\hline Bile duct stricture & 100.0 & 0.0 \\
\hline Pancreatic duct stricture & 97.8 & 2.2 \\
\hline Total & 100.0 & 0.0 \\
\hline
\end{tabular}

Abbreviations: $\mathrm{CA}$, cancer; $\mathrm{CBD}$, common bile duct.

(US\$8.8 million). Should DRG version 6 be in effect, the subsidy would rise to 324.0 million Baht (US\$9.8 million). When counting only day surgery, the reimbursed budget amounted to 12.4 million Baht (US\$0.38 million) for DRG version 5 and increased to 12.8 million Baht (US\$ 0.39 million) for DRG version 6. If the new reimbursement policy (using RW instead of adjRW in the payment calculation) were introduced, the additional budget would cost between 0.18 and 1.94 million Baht (US\$5,530 to US\$58,903), depending on different versions of DRG and different utilization scenarios. Scenario B2 (all candidate procedures became day surgery and DRG version 6 was applied) estimated the largest extra budget impact. Regional hospitals, university hospitals, and general hospitals would benefit most from the new reimbursement policy compared to other facility types.
With the findings above, it seems that the new reimbursement policy would lead to minimal extra budget burden. Even in the maximum utilization scenario, the reimbursement budget would increase by just about 15\% (1.94 million Baht increase from the existing 12.4 million Baht spending). The small increment of budget required was explained by the fact that the difference between RW and adjRW was infinitesimal and the preconditions for reimbursement were quite stringent (such as the patient must have "improved" discharge status and must be diagnosed in certain diagnoses which are specified in the list only).

Besides, there are few worth discussing observations. First, university and regional hospitals appear to benefit most from the new reimbursement policy than lower-level facilities, especially district hospitals and health centers. A likely explanation for this phenomenon is most procedures performed at university and regional hospitals were for complicated diseases in which the difference between adjRW and RW for day surgery was quite large. In contrast, the disparity between adjRW and RW for relatively simple diagnoses (such as hydrocele and inguinal hernia), which were mostly concentrated in lower-level facilities, was quite inconsequential. Therefore, should the MOPH aim to promote access to day surgery among patients in rural areas (most of which are under the catchment areas of district hospitals), there should be other mechanisms apart from this reimbursement policy to incentivize providers to perform day surgery in lower-level facility settings.

Second, even without the new reimbursement policy, DRG version 6 was likely to bring about additional revenue to the facilities, relative to DRG version 5. This issue might be another policy option, that is, policymakers might expedite 


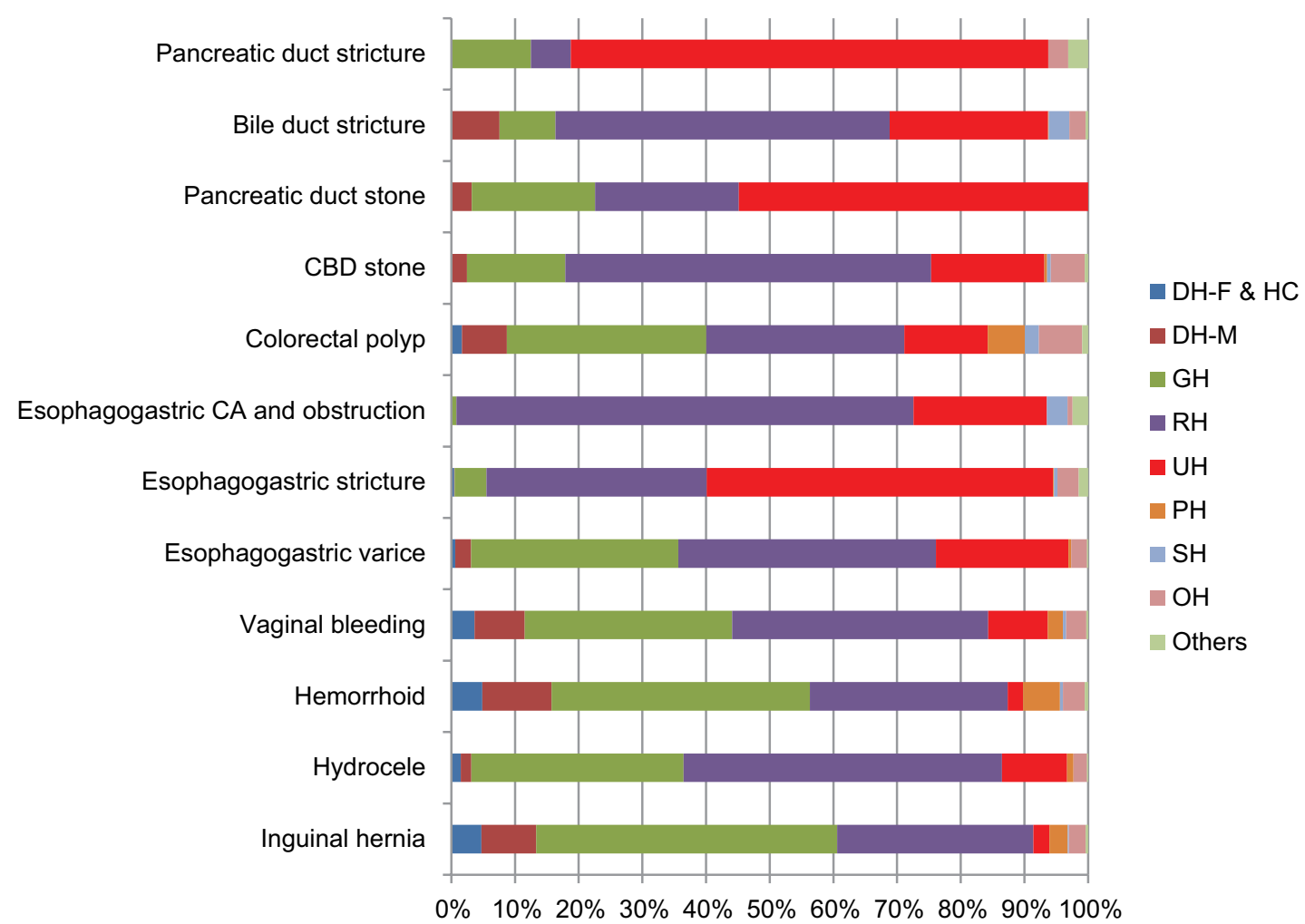

Figure 3 Distribution of admissions with candidate procedures across facility types between FY 2014 and FY 2016.

Abbreviations: CA, cancer; CBD, common bile duct; FY, fiscal year; DH-F \& HC, small district hospitals and health centers; DH-M, medium-to-large district hospitals; GH, general or provincial hospitals; MOPH, Thai Ministry of Public Health; $\mathrm{OH}$, hospitals not affiliated to the MOPH; $\mathrm{PH}$, private hospitals; $\mathrm{RH}$, regional hospitals; $\mathrm{SH}$, specialized hospitals; UH, university hospitals.

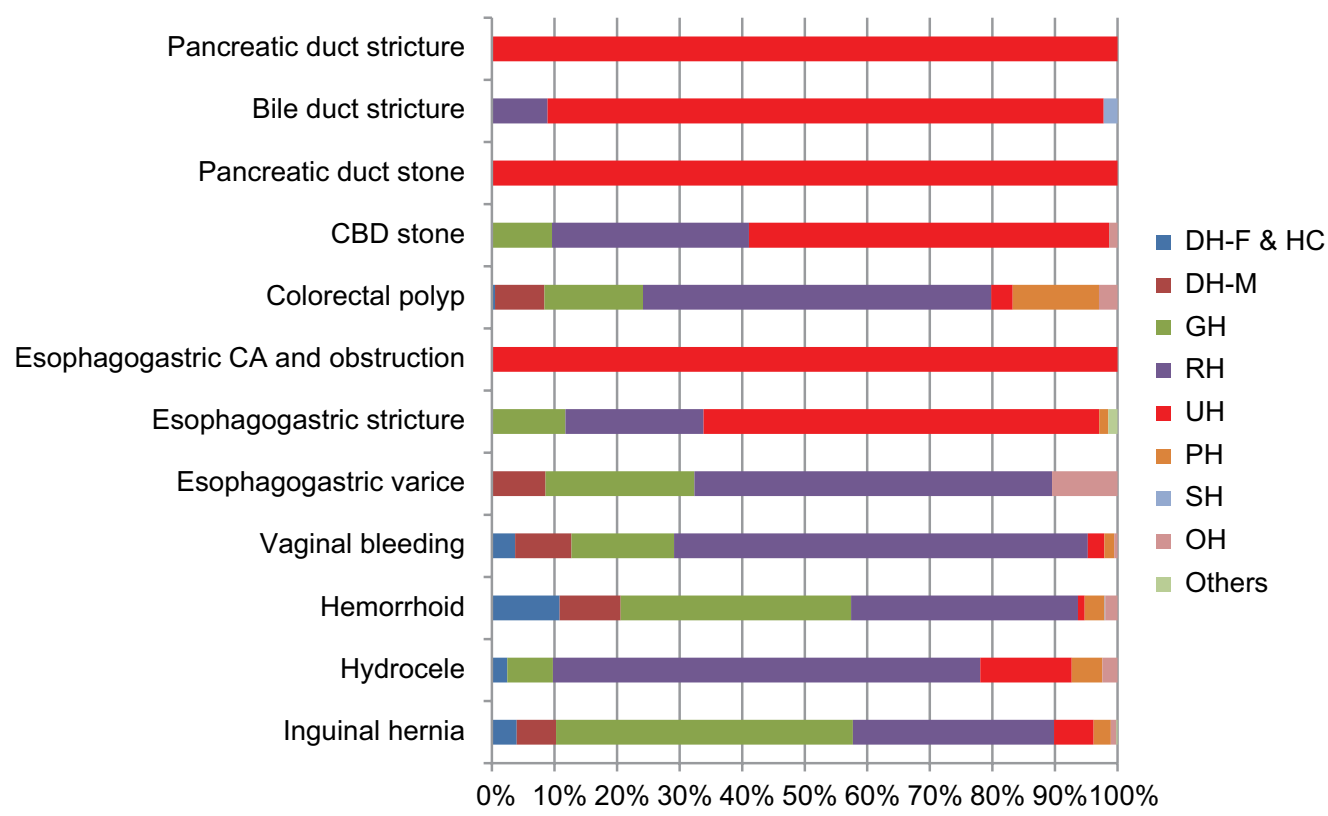

Figure 4 Distribution of day surgery admissions across facility types between FY 2014 and FY 2016.

Abbreviations: $\mathrm{CA}$, cancer; $\mathrm{CBD}$, common bile duct; $\mathrm{FY}$, fiscal year; DH-F \& HC, small district hospitals and health centers; $\mathrm{DH}-\mathrm{M}$, medium-to-large district hospitals; GH, general or provincial hospitals; MOPH, Thai Ministry of Public Health; $\mathrm{OH}$, hospitals not affiliated to the MOPH; $\mathrm{PH}$, private hospitals; RH, regional hospitals; SH, specialized hospitals; UH, university hospitals. 
Mean RW DRG V5 Mean RW DRG V6 Mean adjRW DRG V5 - Mean adjRW DRG V6

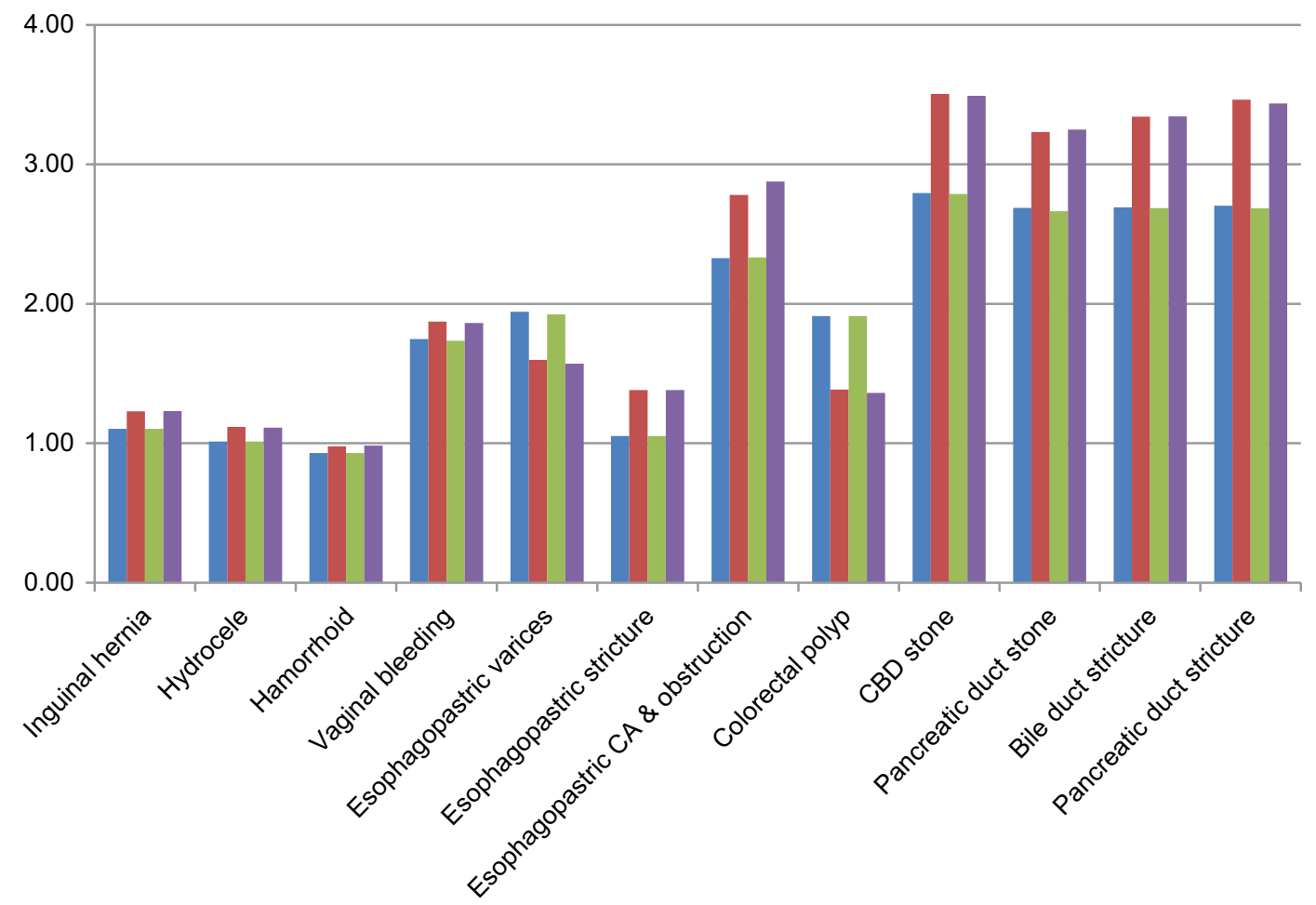

Figure $5 \mathrm{CMI}$ analysis for all admissions with candidate procedures according to DRG versions 5 and 6 .

Abbreviations: adjRW, adjusted relative weight; $C A$, cancer; $C B D$, common bile duct; CMI, case mix index; DRG, diagnostic related group; RW, relative weight; $V$, version.

the implementation of DRG version 6 first to incentivize health care providers while awaiting full implementation of the new reimbursement policy.

This study has both strengths and limitations. Regarding strengths, the study used individual patient records from the whole national dataset of the NHSO. This approach directly helped increase the generalizability power of the research.

Regarding limitations, there are certain important issues, as follows. First, this paper presented a single-country case study. Hence its external validity is quite limited. The findings can (at the very least) be applied only to countries where their health service system is quite similar to Thailand. Nonetheless it does not mean that lessons from Thailand are of little value to other nations. One of the key lessons was financing policy alone might not be able to create a significant boost on day surgery volume. The policy itself was based on a presumption that the new payment mechanism was the only key driver causing the change in day surgery performance among providers, but, in reality, there are many other factors that might affect the degrees of policy uptake. This point is linked to the concept of day surgery as presented earlier in the "Introduction" section. That is, day surgery is not merely a matter of "time" management. The foundation of day surgery practice necessitates well-founded infrastructure that can support the whole course of care, including sufficient beds in surgical, anesthetic wards, available intensive care units, well-designed pre- and post operative rooms with practical patient management guidelines, well-functioning diagnostic devices and data management systems, and adequate number of qualified health staff. ${ }^{5,15,18,19}$ Thus, the real-world situation might differ from the proposed scenarios since it depends on the readiness of health facilities as to whether and to what extent the providers were capable of accommodating the eligible cases in accordance with acceptable standards of care. Other supporting policies, such as health workforce preparedness, infrastructure development, and rigorous quality control procedures, should be promulgated in parallel. This point should be considered meticulously especially for countries where the day surgery policy is at an early stage policy formulation and/or policy implementation. ${ }^{20}$

Second, the cost saving benefit from performing day operations was not comprehensively captured in this paper. Though the authors had provided some insight about potential savings from day surgery through the analysis on the claim for treatment expenses (see Results section), the claim itself is literally not a perfect indicator for "cost" of care. This 


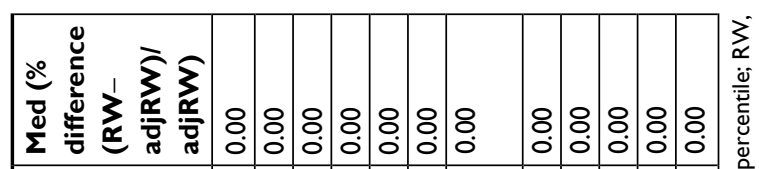

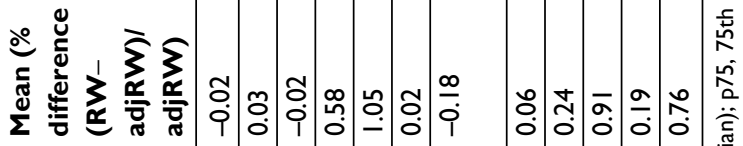

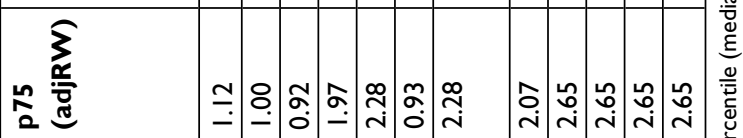

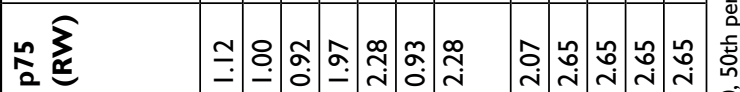

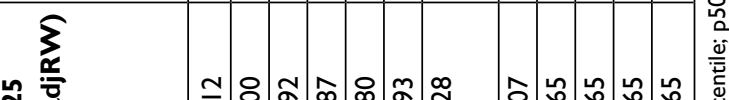

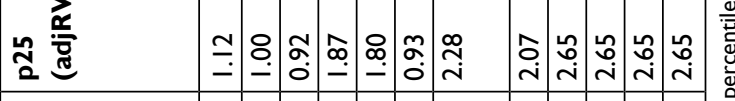
鲜 (8)

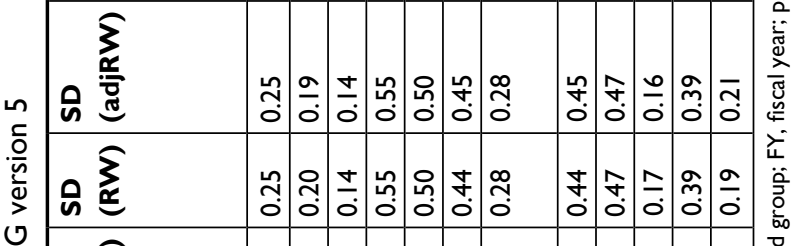

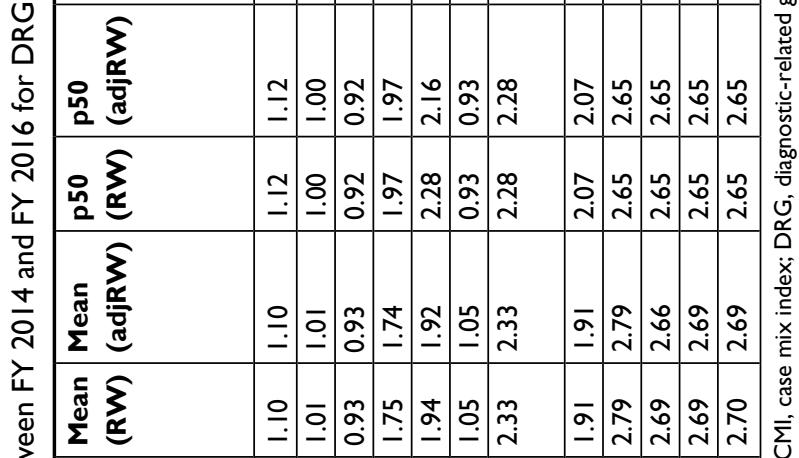

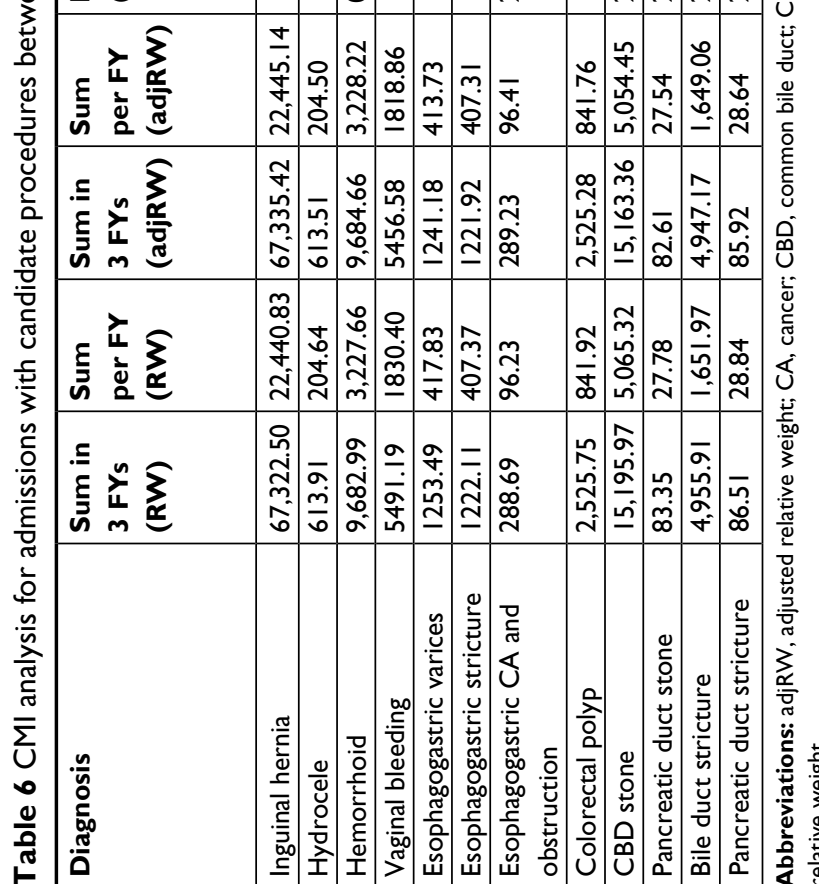

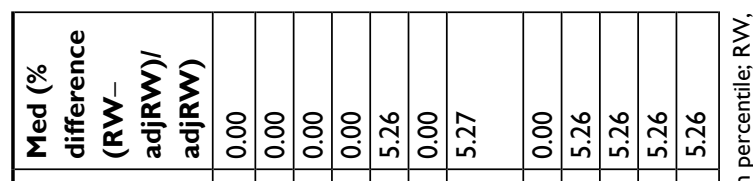

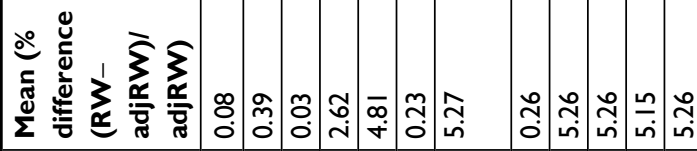

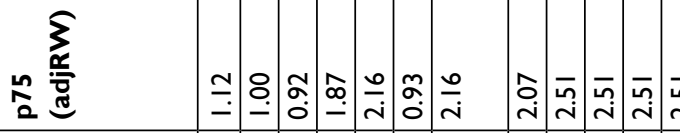

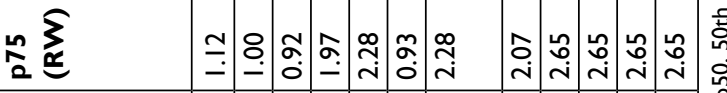

范誉

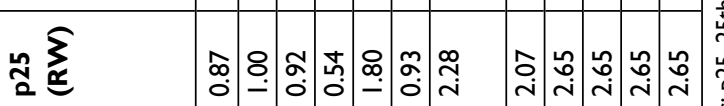

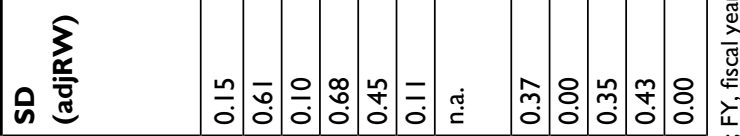

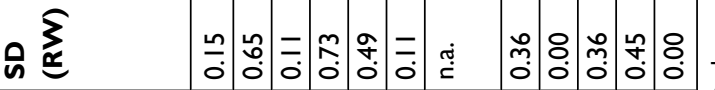

\begin{tabular}{|c|c|c|c|c|c|c|c|c|c|c|c|}
\hline 员 & $\cong$ & : & $\begin{array}{lll} \\
\vdots \\
0\end{array}$ & 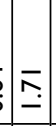 & $\begin{array}{l}m \\
\sigma \\
\sigma\end{array}$ & $\frac{0}{i}$ & $\mid \begin{array}{l}\hat{i} \\
\text { in }\end{array}$ & 芯 & $\stackrel{\text { In }}{\mathrm{N}}$ & $\stackrel{\bar{n}}{n}$ & 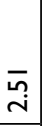 \\
\hline 율ำ & $\cong$ & ב̊: & $\begin{array}{lll} \\
\vdots \\
\vdots\end{array}$ & 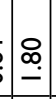 & $\begin{array}{l}m \\
\sigma \\
\delta\end{array}$ & $\stackrel{\infty}{\underset{\sim}{\sim}}$ & $\begin{array}{l}\hat{i} \\
\dot{i}\end{array}$ & $\begin{array}{l}\stackrel{0}{0} \\
\stackrel{n}{*}\end{array}$ & $\begin{array}{l}\stackrel{2}{0} \\
\text { in }\end{array}$ & & $\begin{array}{l}\text { L } \\
\text { in }\end{array}$ \\
\hline 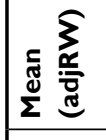 & $\stackrel{0}{-}$ & $\bar{\equiv}$ & 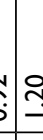 & 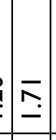 & $\begin{array}{l}m \\
\tilde{o} \\
\delta\end{array}$ & $\stackrel{\mathscr{0}}{i}$ & $\stackrel{\sim}{\varrho}$ & $\overline{\tilde{N}}$ & $\begin{array}{l}\hat{o} \\
\stackrel{i}{ }\end{array}$ & & $\stackrel{\sim}{\sim}$ \\
\hline 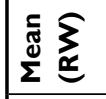 & $\stackrel{\circ}{\circ}$ & $\cong$ & 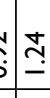 & $\stackrel{?}{=}$ & $\begin{array}{l}m \\
0 \\
0\end{array}$ & $\underset{\sim}{\infty}$ & $\stackrel{0}{2}$ & $\begin{array}{l}0 \\
0 \\
\end{array}$ & & 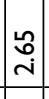 & $\begin{array}{l}\stackrel{0}{0} \\
\stackrel{i}{i}\end{array}$ \\
\hline
\end{tabular}

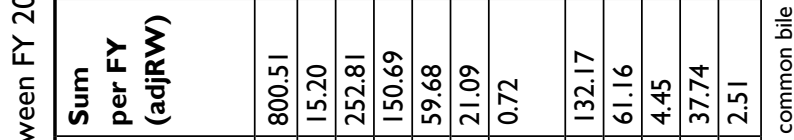

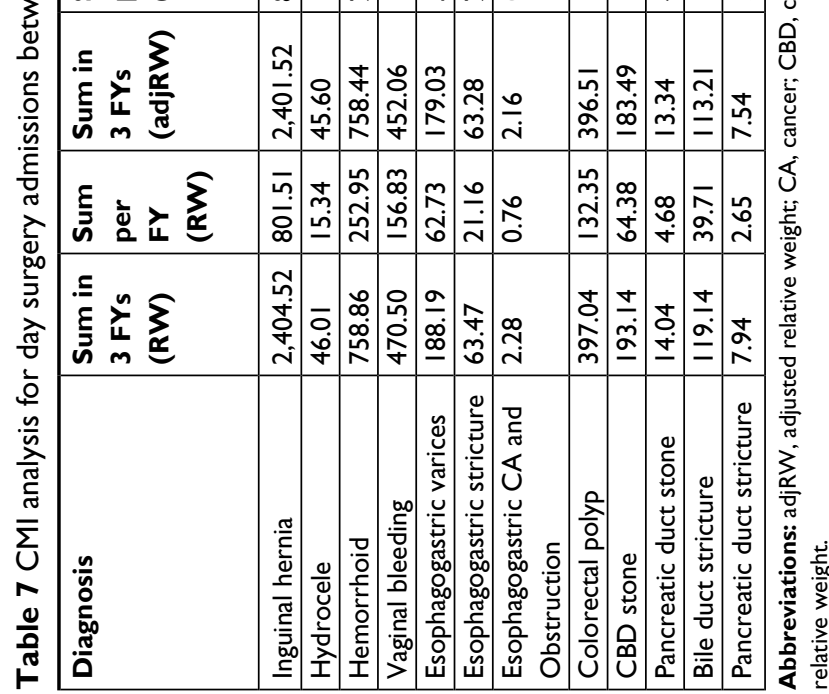




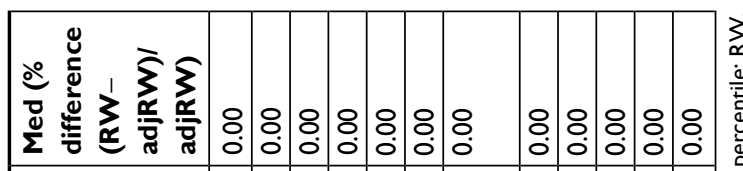

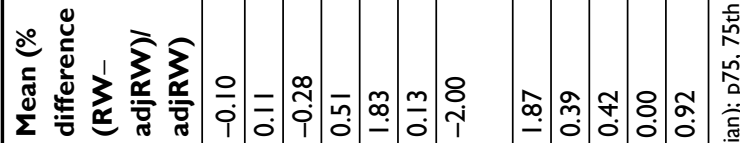

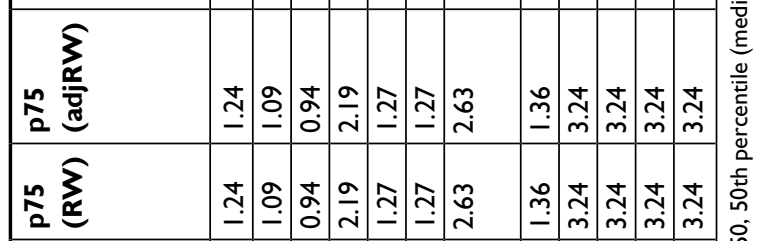

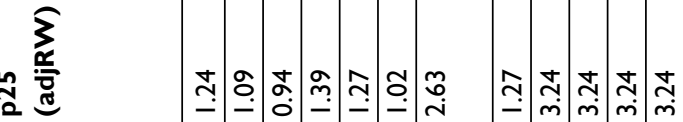

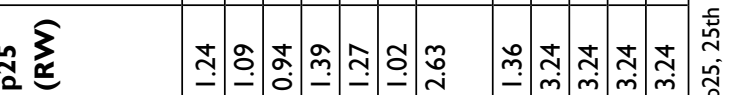

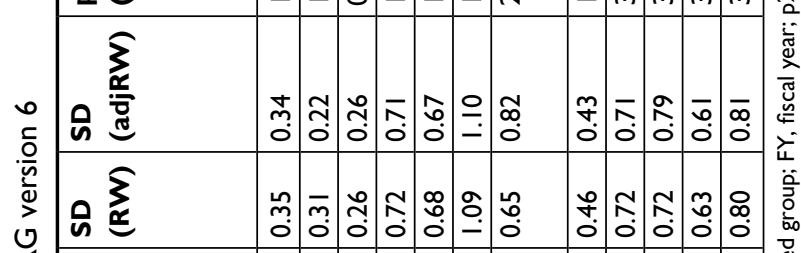

党

\begin{tabular}{|c|c|c|c|c|c|c|c|c|c|c|}
\hline 络 & $\stackrel{⿱ 亠 䒑}{\longrightarrow}$ & & $\frac{\sigma}{i}$ & $\stackrel{\overbrace{}}{\beth}$ & 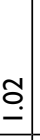 & 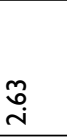 & & & & $\underset{m}{\stackrel{d}{m}}$ \\
\hline 足余 & $\stackrel{ \pm}{\longrightarrow}$ & ô.|Z & $\frac{a}{i}$ & 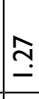 & 宓 & 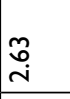 & $\stackrel{\oplus}{-}$ & & & 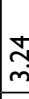 \\
\hline 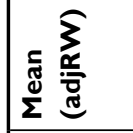 & $\stackrel{\oplus}{\longrightarrow}$ & $=\stackrel{0}{=0}$ & $\stackrel{\infty}{\infty}$ & 望 & 羂. & 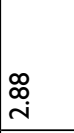 & $\stackrel{m}{-}$ & & 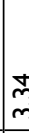 & $\begin{array}{l}f \\
m \\
m\end{array}$ \\
\hline $\begin{array}{l}\text { ॠ } \\
\Sigma \\
\Sigma\end{array}$ & 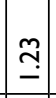 & $\stackrel{2}{=} \stackrel{0}{\circ}$ & $\stackrel{\infty}{-\infty}$ & $\stackrel{\circ}{\circ}$ & $\stackrel{\substack{m \\
\hdashline}}{\longrightarrow}$ & $\stackrel{\infty}{\stackrel{\infty}{\sim}}$ & : & & $\Phi$ & $\begin{array}{l}0 \\
m \\
m\end{array}$ \\
\hline 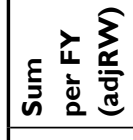 & 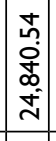 & 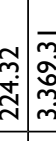 & $\begin{array}{l}0 \\
0 \\
\infty \\
\alpha \\
- \\
-1\end{array}$ & $\begin{array}{l}\text { o } \\
\dot{\mathrm{j}} \\
\text { m }\end{array}$ & $\begin{array}{l}\hat{N} \\
0 \\
0 \\
\end{array}$ & 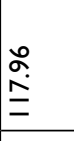 & 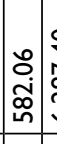 & 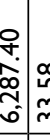 & & $\mid$ \\
\hline 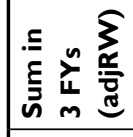 & 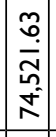 & 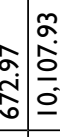 & 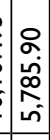 & $\begin{array}{l}0 \\
0 \\
0 \\
0 \\
- \\
-\end{array}$ & 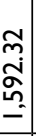 & 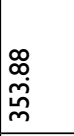 & 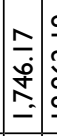 & 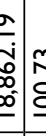 & ป & 으 \\
\hline 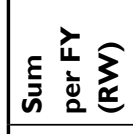 & 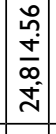 & 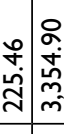 & $\begin{array}{l}\alpha \\
\alpha \\
\alpha \\
\alpha \\
\alpha \\
-\end{array}$ & $\begin{array}{l}\hat{N} \\
\text { Oे } \\
\text { m }\end{array}$ & & \begin{tabular}{|l}
8 \\
$\dot{+}$ \\
\\
\end{tabular} & 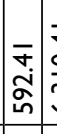 & 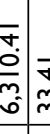 & & \\
\hline 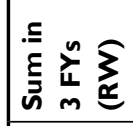 & $\mid \begin{array}{c}0 \\
0 \\
\dot{j} \\
\dot{j} \\
\dot{N} \\
\\
\end{array}$ & 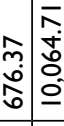 & $\begin{array}{l}\frac{\infty}{\alpha} \\
\frac{\infty}{\alpha} \\
\infty \\
\omega\end{array}$ & \begin{tabular}{|l}
$\bar{\infty}$ \\
0 \\
0 \\
$\vdots$ \\
-
\end{tabular} & & \begin{tabular}{|l}
$\bar{j}$ \\
$\dot{j}$ \\
\\
\end{tabular} & 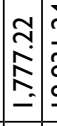 & 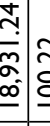 & $\mathrm{s}$ & \\
\hline 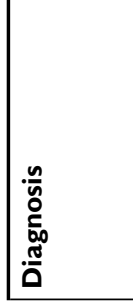 & 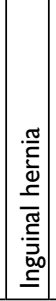 & 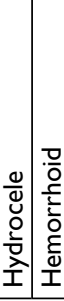 & 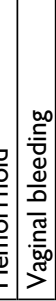 & 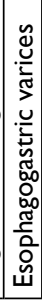 & & 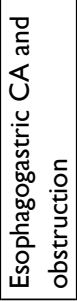 & 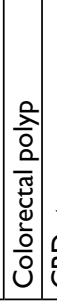 & 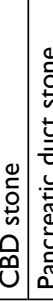 & & 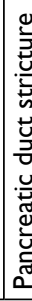 \\
\hline
\end{tabular}

\begin{tabular}{|c|c|c|c|c|c|c|c|c|c|}
\hline 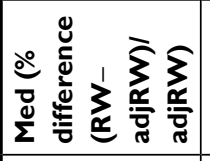 & 80 & 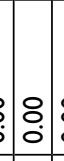 & 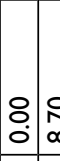 & 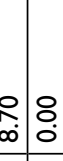 & $\begin{array}{l}R \\
\infty \\
\infty\end{array}$ & $\begin{array}{ll}R \\
\substack{R \\
\infty} \\
\infty\end{array}$ & $\begin{array}{l}? \\
0 \\
0\end{array}$ & & $\begin{array}{l}R \\
\infty \\
\infty\end{array}$ \\
\hline 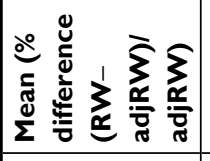 & 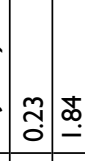 & 放 & 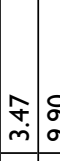 & 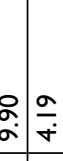 & $\begin{array}{c}R \\
\infty \\
\infty\end{array}$ & 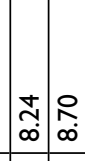 & 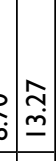 & & $\begin{array}{l}R \\
\infty \\
\infty\end{array}$ \\
\hline 玆 & $\stackrel{ \pm}{\stackrel{ \pm}{-}}$ & $\begin{array}{l}a \\
0 \\
0\end{array}$ & $\dot{i}_{i}=$ & $=$ & ב̃ & $\stackrel{\infty}{\underset{\sim}{*} \stackrel{\infty}{\sim}}$ & 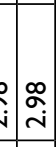 & & $\begin{array}{l}\infty \\
\stackrel{\infty}{2} \\
i\end{array}$ \\
\hline 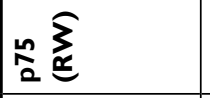 & 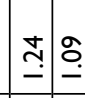 & $\begin{array}{l}0 \\
\vdots \\
0\end{array}$ & $\frac{\sigma}{i}$ & 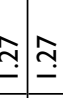 & 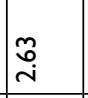 & 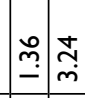 & 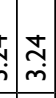 & & $\underset{m}{\stackrel{\sim}{\pi}}$ \\
\hline 离 & o. & $\mid \begin{array}{l}\pi \\
0 \\
0\end{array}$ & בُ & $=\underline{-} \tilde{c}$ & $\underset{\text { I }}{\mathcal{N}}$ & 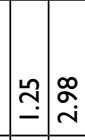 & 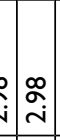 & & $\begin{array}{l}\infty \\
\stackrel{\infty}{\sim} \\
\end{array}$ \\
\hline 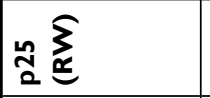 & ๙2. & $\begin{array}{l}\vdots \\
\vdots \\
0 \\
0\end{array}$ & I̊: & 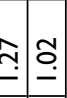 & $\begin{array}{l}3 \\
\text { in } \\
\text { in }\end{array}$ & 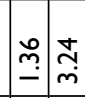 & 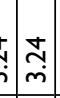 & & $\underset{m}{\stackrel{\sim}{*}}$ \\
\hline 怘突 & 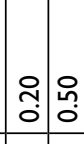 & $\frac{0}{0}$ & \begin{tabular}{|cc} 
& \\
& 3 \\
0 & 3 \\
0
\end{tabular} & \begin{tabular}{lll} 
& \\
\multirow{S}{0}{} & $\widehat{m}$ \\
0 & 0 \\
\end{tabular} & 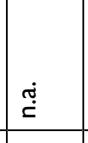 & $\begin{array}{ll}\frac{m}{0} & 8 \\
\end{array}$ & \begin{tabular}{|l|l|} 
\\
\end{tabular} & & $\begin{array}{l}8 \\
0 \\
\end{array}$ \\
\hline 虽奚 & 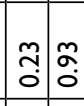 & : & 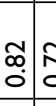 & 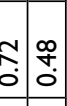 & 夰 & $\stackrel{2}{\circ}$ & 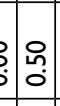 & & 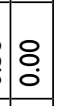 \\
\hline 点 & 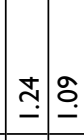 & $\mid \begin{array}{l}\pi \\
0 \\
0\end{array}$ & 菖 & 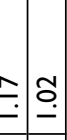 & $\underset{\mathrm{i}}{\mathcal{A}}$ & 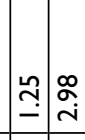 & 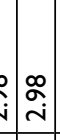 & & 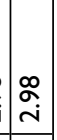 \\
\hline 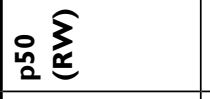 & 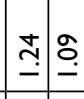 & $\left(\begin{array}{l}\pi \\
0 \\
0\end{array}\right.$ & I. & 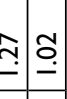 & $\underset{\substack{0 \\
\text { in }}}{ }$ & 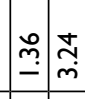 & 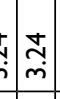 & & $\underset{\sim}{\stackrel{\leftarrow}{n}}$ \\
\hline 疍 & $\stackrel{ \pm}{=} \stackrel{\infty}{=}$ & 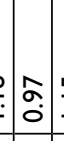 & $\stackrel{n}{=}$ & $\stackrel{?}{\stackrel{0}{*}} \stackrel{\circ}{=}$ & $\stackrel{\mathcal{Z}}{\mathcal{Z}}$ & 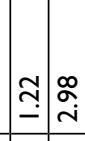 & 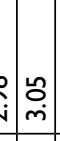 & & $\begin{array}{l}\infty \\
\stackrel{2}{i} \\
i\end{array}$ \\
\hline 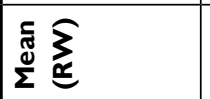 & 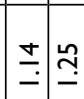 & 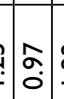 & $\underset{\Xi}{\underline{\Xi}}$ & 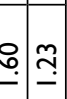 & ڤై & 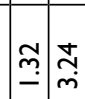 & 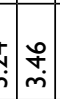 & & $\underset{m}{\stackrel{J}{m}}$ \\
\hline 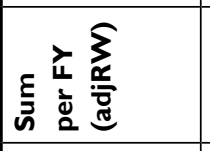 & \begin{tabular}{|l|l}
$\stackrel{1}{0}$ & \multirow{0}{0}{} \\
$\infty$ & $\underline{0}$ \\
\end{tabular} & 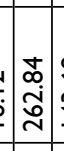 & 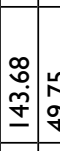 & 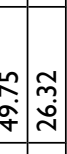 & $\begin{array}{l}\bar{\infty} \\
0 \\
0 \\
\end{array}$ & 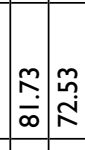 & 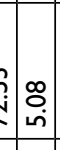 & & 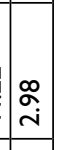 \\
\hline 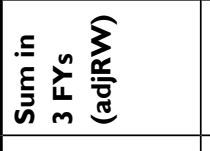 & 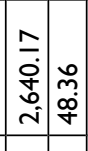 & 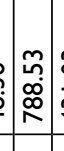 & 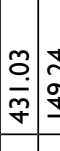 & 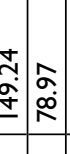 & $\underset{\text { i }}{\mathcal{4}}$ & 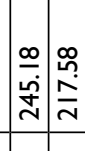 & 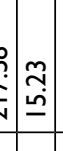 & & $\begin{array}{l}\Delta \\
0 \\
\infty \\
\infty\end{array}$ \\
\hline 点岕 & 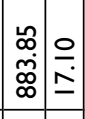 & : & 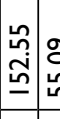 & 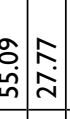 & $\begin{array}{c}\infty \\
\substack{\infty \\
0 \\
0\\
} \\
\end{array}$ & 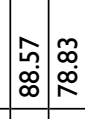 & 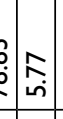 & & $\underset{\sim}{\stackrel{\Delta}{\sim}}$ \\
\hline 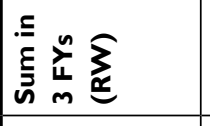 & 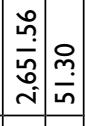 & 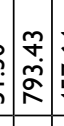 & 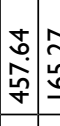 & 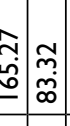 & 艿 & 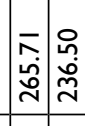 & 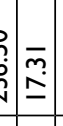 & & $\frac{a}{5}$ \\
\hline 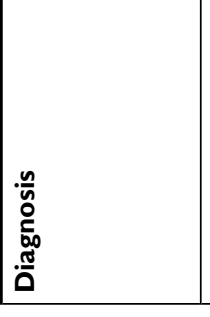 & 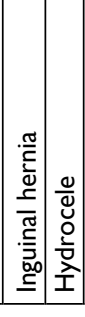 & 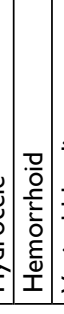 & 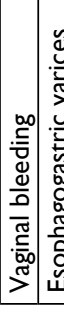 & 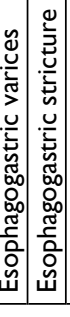 & 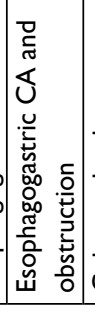 & 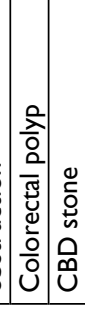 & 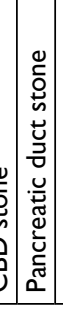 & 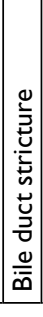 & 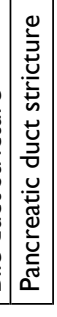 \\
\hline
\end{tabular}




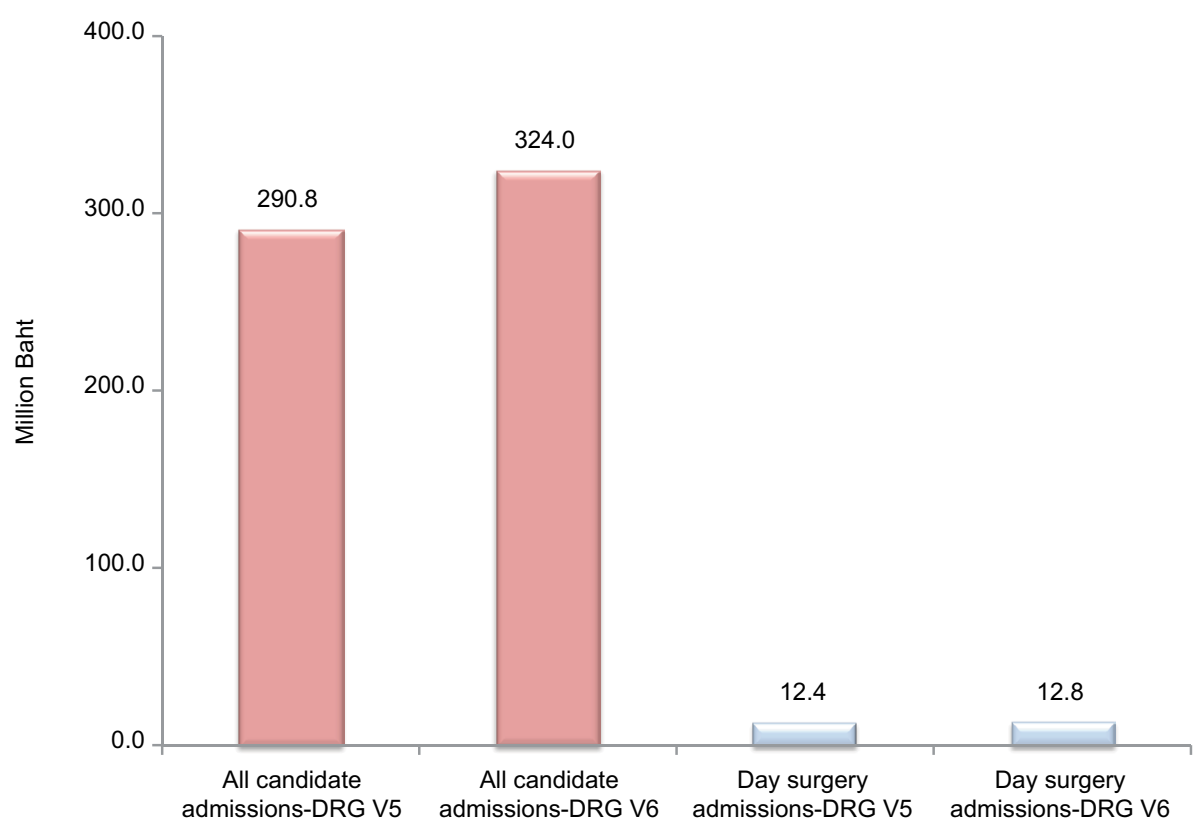

Figure 6 Budget reimbursed for health facilities in all admissions with candidate procedures according to DRG version 5 and DRG version 6 . Abbreviations: DRG, diagnostic-related group; V, version.

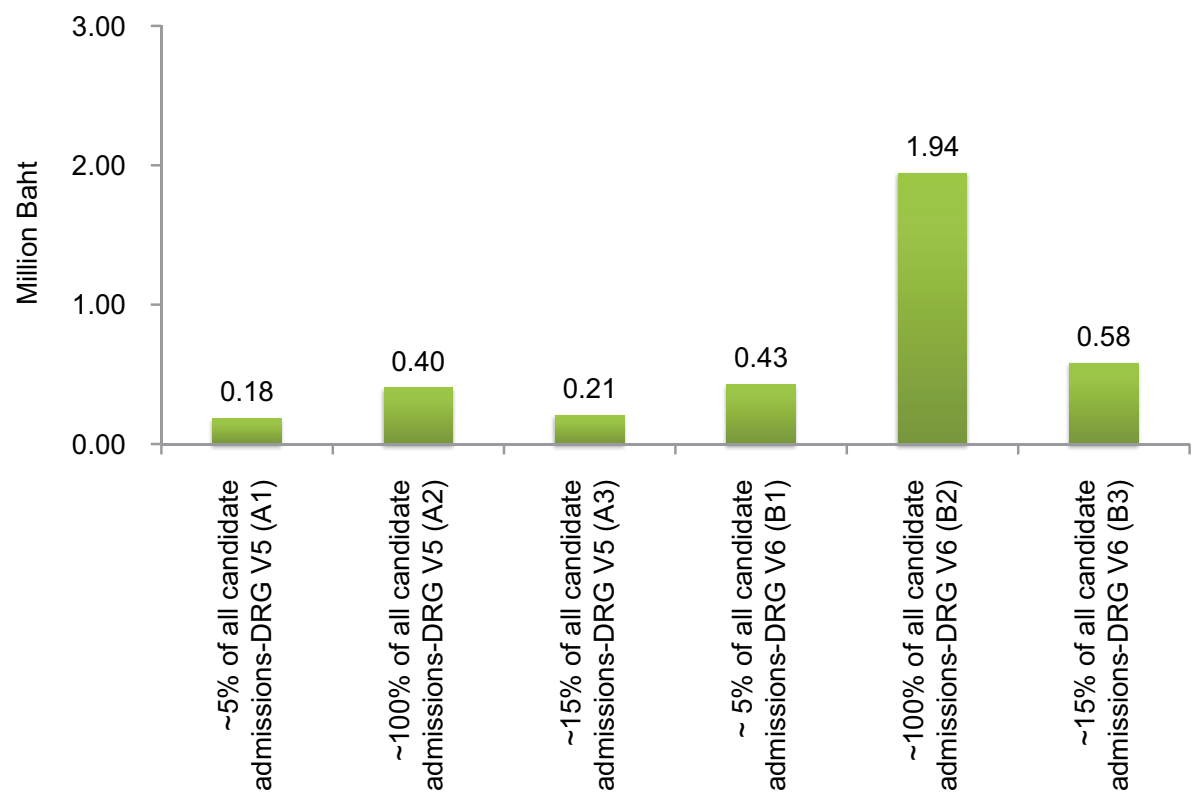

Figure 7 Additional budget impact derived from the new reimbursement policy in different scenarios. Abbreviations: DRG, diagnostic-related group; $\mathrm{V}$, version.

is because most claim items are independently set by each facility and are hugely influenced by many uncontrollable factors, such as room and board and staff's salary. To accurately assess the economic advantage of day surgery through a lens of potential saving, a full "cost" analysis with primary data collection on numerous cost items (such as capital cost, labor cost, and material cost) is recommended.
Last, the inpatient payment mechanism for the Thai health care system applied the concept of DRG with global budget. The term "global budget" means the NHSO set the ceiling for the total payment to health facilities at the beginning of each fiscal year, rather than leaving it as open-ended payment. ${ }^{7,21}$ Therefore, the base rate per CMI might vary in each year depending on the budget acquired from the government. As 

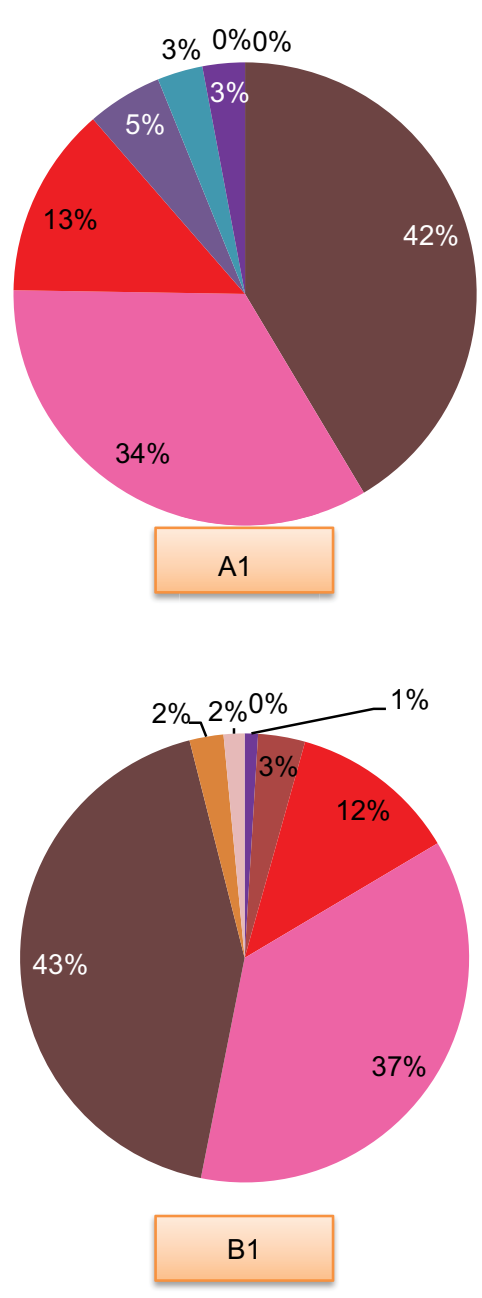

DH-F \& HC
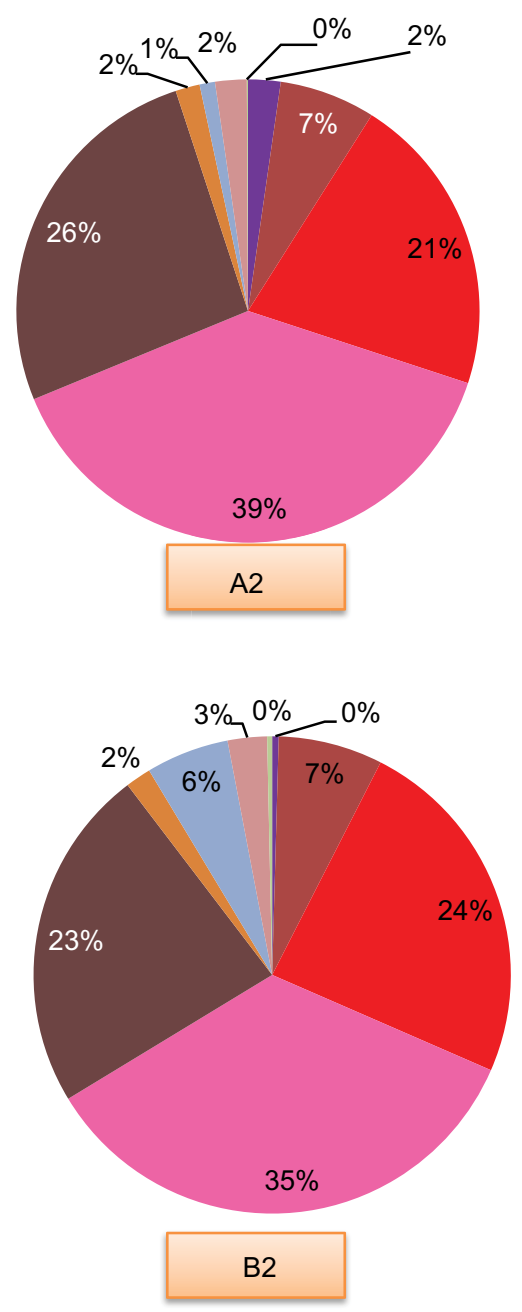

DH-M
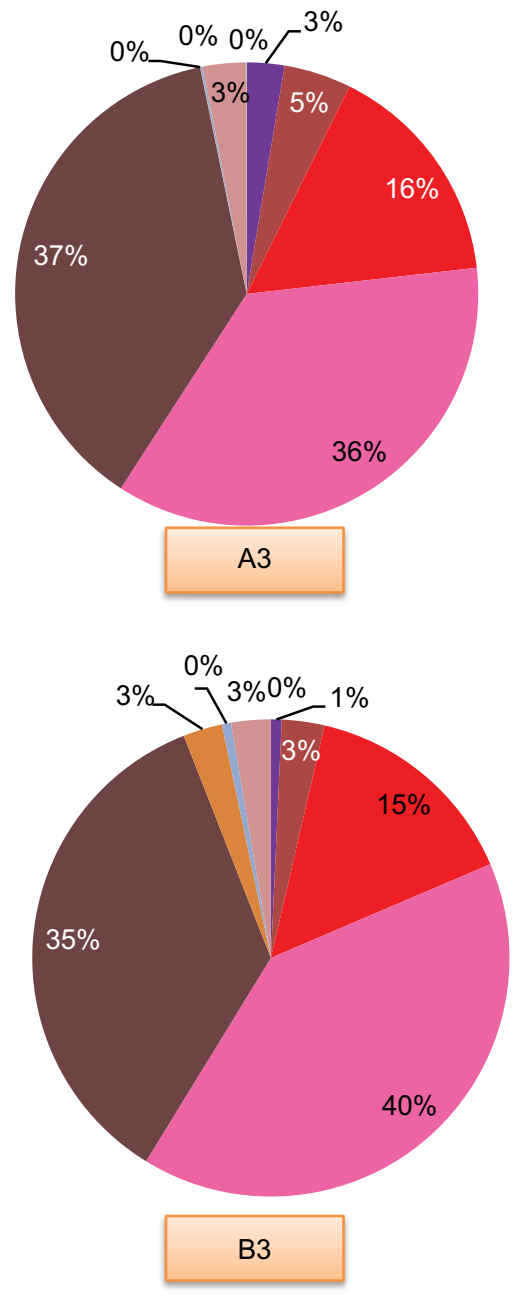

$\mathrm{SH}$

$\mathrm{OH}$

Others

Figure 8 Distribution of additional budget for each facility type in different scenarios.

Notes: Scenario: AI = DRG version 5 and day surgery cases account for $5 \%$ of candidate procedures. A2 = DRG version 5 and day surgery cases account for $100 \%$ of candidate procedures. A3 = DRG version 5 and day surgery cases account for $15 \%$ of candidate procedures. BI = DRG version 6 and day surgery cases account for $5 \%$ of candidate procedures. B2 = DRG version 6 and day surgery cases account for $100 \%$ of candidate procedures. B3 = DRG version 6 and day surgery cases account for $15 \%$ of candidate procedures.

Abbreviations: DH-F \& HC, small district hospitals and health centers; DH-M, medium-to-large district hospitals; DRG, diagnostic-related groups; GH, general or provincial hospitals; $\mathrm{OH}$, hospitals not affiliated to the Thai Ministry of Public Health; PH, private hospitals; RH, regional hospitals; SH, specialized hospitals; UH, university hospitals.

a result, it is not guaranteed that the facilities performing day surgery will earn additional revenue as expected in the following year, as the base rate may shrink from the previous year. Nonetheless, it is very likely that the more health facilities performed day surgery the more they enjoyed economic gain. This is because, with shorter stay, it is likely to have more available beds and an increasing turnover rate patients, rendering a larger feasibility to recruit additional day surgery cases. The potential economic gain is also derived from the fact that a facility would bear a smaller unit cost from a shorter length of stay while still able to claim its expense at the unadjusted rate (adjRW instead of RW) as if the length of stay lasted $>1$ day.

\section{Conclusions}

The new reimbursement policy would result in minimal incremental budget burden. Even in cases of full policy uptake (all candidate procedures were performed as day surgery and DRG version 6 was in place), the needed budget would increase by $15 \%$. The small incremental change was because the difference between RW and adjRW was quite infinitesimal. University and regional hospitals seem to benefit most from the new reimbursement policy. Therefore, if the MOPH aims to promote access to day surgery district and provincial hospitals, there should be other mechanisms to incentivize providers to perform day surgery in the rural settings. Besides, the promotion of day surgery 
should focus not only on the financial angle. The qualitative aspects of the policy are of equal or even more importance, such as the establishment of well-equipped surgical units, clear patient management guidelines, and adequate health staff in terms of both quality and quantity.

\section{Abbreviations}

adjRW, adjusted relative weight; $\mathrm{CA}$, cancer; $\mathrm{CMI}$, case mix index; CBD, common bile duct; DMS, Department of Medical Services; DRG, diagnostic-related groups; FY, fiscal year; $\mathrm{GH}$, general or provincial hospitals; $\mathrm{OH}$, hospitals not affiliated to the MOPH; LC, laparoscopic cholecystectomy; DH-M, medium-to-large district hospitals; MOPH, Ministry of Public Health; NHSO, National Health Security Office; $\mathrm{PH}$, private hospitals; $\mathrm{RH}$, regional hospitals; RW, relative weight; DH-F \& HC, small district hospitals and health centers; SH, specialist hospitals; UCS, Universal Coverage Scheme; UH, university hospitals.

\section{Ethics approval and consent to participate}

The dataset used in this study contains individual UCS inpatient records collected by the NHSO as part of its routine monitoring. The NHSO is the legal governing body of the UCS, thus the NHSO is not required to obtain signed consent from each individual patient. However, according to Article 25 of the 1997 Official Information Act and Article 7 of the 2007 National Health Act, the NHSO must ensure confidentiality of data collected and reported. In this study, the researchers strictly followed the confidentiality requirement specified in the aforementioned bylaws. All individual information was strictly kept confidential and not reported in the paper.

\section{Availability of data and materials}

The data appearing in this article were under license for the current study only and are not publicly available. However, the data are available upon reasonable request, conditional upon the permission of NHSO.

\section{Acknowledgments}

The authors would like to thank the NHSO staff for their continuous support. The invaluable advice from Dr Suwit Wibulpolprasert, senior advisor of the MOPH, and Dr Jadej Thammathacharee, deputy secretary-general of the NHSO, is much appreciated. This research was funded by the core resources of the International Health Policy Program. The
NHSO provided in-kind support, such as a meeting venue and documents.

\section{Author contributions}

All authors contributed toward data analysis, drafting and critically revising the paper, gave final approval of the version to be published, and agree to be accountable for all aspects of the work.

\section{Disclosure}

JT and KS are NHSO staff, but neither received any extra revenue for this research apart from their regular monthly salary, nor were they involved in the policy decision making process. The authors report no other conflicts of interest in this work.

\section{References}

1. Lemos P, Jarrett P, Philip BK. Day Surgery: Development and Practice. Brussels: International Association for Ambulatory Surgery; 2006.

2. Gurusamy K, Samraj K, Gluud C, Wilson E, Davidson BR. Metaanalysis of randomized controlled trials on the safety and effectiveness of early versus delayed laparoscopic cholecystectomy for acute cholecystitis. Br J Surg. 2010;97(2):141-150.

3. Mitchell JB, Harrow B. Costs and outcomes of inpatient versus outpatient hernia repair. Health Policy. 1994;28(2):143-152.

4. Shepard DS, Walsh J, Munar W, et al. Cost-effectiveness of ambulatory surgery in Cali, Colombia. Health Pol Plann. 1993;8(2): 136-142.

5. Quemby DJ, Stocker ME. Day surgery development and practice: key factors for a successful pathway. Cont Educ Anaesth Crit Care Pain. 2014;14(6):256-261.

6. Srisawasdi S, Punjasawadwong Y, Werawatganon T, et al. The Thai anesthesia incidents study (Thai study) of ambulatory anesthesia: Part I: method, geographic distribution and population. J Med Assoc Thai. 2007;90(8):1558-1564.

7. Evans T, Chowdhury A, Evans D, Fidler A, Lindelow M, Mills A. Thailand's Universal Coverage Scheme: Achievements and Challenges. An independent assessment of the first 10 years (2001-2010). Nonthaburi, Thailand: Health Insurance System Research Office; 2012.

8. Tangcharoensathien V, Limwattananon S, Patcharanarumol W, Thammatacharee J, Jongudomsuk P, Sirilak S. Achieving universal health coverage goals in Thailand: the vital role of strategic purchasing. Health Policy Plan. 2015;30(9):1152-1161.

9. Troy AM, Cunningham AJ. Ambulatory surgery: an overview. Curr Opin Anaesthesiol. 2002;15(6):647-657.

10. Hfocus. Piloting 12 diseases for day surgery. Udonthani: Hfocus; 2017 [March 25, 2018]; Available from: https://www.hfocus.org/ content/2017/12/15085.

11. Mull HJ, Rivard PE, Legler A, et al. Comparing definitions of outpatient surgery: implications for quality measurement. Am J Surg. 2017;214(2):186-192.

12. Moody FG, Andrews B, editors. Atlas of Ambulatory Surgery. Philadelphia: W.B. Saunders Company; 1999.

13. Kopp SL, Horlocker TT. Regional anaesthesia in day-stay and short-stay surgery. Anaesthesia. 2010;65(Suppl 1):84-96.

14. International Association for Ambulatory Surgery. Ambulatory (day) surgery: Suggested international terminology and definitions. London: Royal College of Surgeons; 2003 [November 9, 2018]; Available from: http://www.iaas-med.com/files/historical/IAAS_definitions.pdf. 
15. Castoro C, Bertinato L, Baccaglini U, Drace CA, McKee M. Policy brief-Day surgery: making it happen. Copenhagen: WHO Regional Office for Europe; 2007 [April 4, 2018]; Available from: http://www. euro.who.int/_data/assets/pdf_file/0011/108965/E90295.pdf?ua=1.

16. Verma R, Alladi R, Jackson I, Johnston I, Kumar C, Page R. Day case and short stay surgery: 2. Anaesthesia. 2011;66(5):417-434.

17. Baskerville P. A new vision for day surgery. $J$ Perioper Pract. 2006;16(7):327-328, 30, 32 .

18. Stephenson ME. Discharge criteria in day surgery. $J A d v$ Nurs. 1990;15(5):601-613.
19. Kothari AN, Zapf MA, Blackwell RH, et al. Components of hospital perioperative infrastructure can overcome the weekend effect in urgent general surgery procedures. Ann Surg. 2015;262(4):683-691.

20. Berryman JM. Development and organization of outpatient surgery units: the hospital's perspective. Urol Clin North Am. 1987;14(1):1-9.

21. Pannarunothai S. Lesson learned from Thailand DRG and Global budget (mixed payment). Pitsanulok: Centre for Health Equity Monitoring Foundation; 2017 [April 5, 2018]; Available from: http://www.kpmakugm.org/id/assets/public/DRG\%20UGM\%2015\%20Mar\%2017\%20 upload.pdf.
Risk Management and Healthcare Policy

\section{Publish your work in this journal}

Risk Management and Healthcare Policy is an international, peer-reviewed, open access journal focusing on all aspects of public health, policy, and preventative measures to promote good health and improve morbidity and mortality in the population. The journal welcomes submitted papers covering original research, basic science, clinical and epidemiological studies, reviews and evaluations, guidelines, expert opinion and commentary, case reports and extended reports. The manuscript management system is completely online and includes a very quick and fair peerreview system, which is all easy to use. Visit http://www.dovepress.com/ testimonials.php to read real quotes from published authors. 